\title{
FORT COLLINS SCIENCE CENTER Invasive Species Science
}

\section{Capabilities}

Invasive, non-native species of plants, animals, and disease organisms adversely affect the ecosystems they enter. Like "biological wildfires," they can quickly spread, and they affect nearly all terrestrial and aquatic ecosystems. Invasive species have become the greatest environmental challenge of the 21 st century in terms of economic, environmental, and human health costs, with an estimated impact in the U.S. of over $\$ 138$ billion per year. Managers of Department of the Interior and other public and private lands and waters rank invasive species as their top resource management problem.

The Invasive Species Science Branch of the Fort Collins Science Center (FORT) provides research and technical assistance relating to invasive species management concerns, including understanding how these species are introduced, identifying areas vulnerable to invasion, forecasting invasions, and developing control methods. To disseminate this information, FORT scientists are developing the Invasive Species Information Node of the National Biological Information Infrastructure (NBII), a comprehensive, Web-accessible database of invasive plant and animal species and disease agents. From these data, and in partnership with Colorado State University, the National Aeronautic Space Administration (NASA), and others, FORT scientists are constructing models to understand and predict invasive species behavior for more effective management.

FORT is also the administrative home of the National Institute of Invasive Species Science, a growing consortium of partnerships between government and private organizations established by the U.S. Geological Survey (USGS) and its many cooperators. The Institute was formed to develop cooperative approaches for invasive species science that meet the urgent needs of land managers and the public. Its mission is to work with others to coordinate data and research from many sources to predict and reduce the effects of harmful nonnative plants, animals, and diseases in natural areas and throughout the United States, with a strategic approach to information management, research, modeling, technical assistance, and outreach. The Institute research team will develop local-, regional-, and nationalscale maps of invasive species and identify priority invasive species, vulnerable habitats, and pathways of invasion. County-level and point data on occurrence will be linked to plot-level and site-level information on species abundance and spread. FORT scientists and Institute partners are working to integrate remote sensing data and GIS-based predictive models to track the spread of invasive species across the country. This information will be linked to control and restoration efforts to evaluate their cost-effectiveness. Understanding both successes and failures will advance the science of invasive species containment and control as well as restoration of habitats and native biodiversity.

\section{Selected Projects}

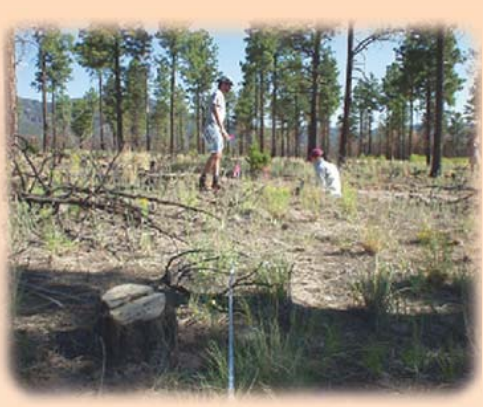

\section{Wildfire, Fuel Treatments, and Non-Native Plant Species}

Increasingly, public land managers are faced with having to protect natural places and processes as well as residents of the wildland-urban interface, where these twin mandates can collide. In collaboration with the Western Forest Fire Research Center at Colorado State University, FORT scientists are conducting research to provide these managers with information that is applicable both ecologically and socially to pre- and post-fire management decisions. Avenues of investigation include the effectiveness of prewildfire fuel reduction treatments on reducing post-fire burn severity; the effects of wildfire on native and non-native plant species; and the interaction between seeded species and native plant species.

\section{National Wildlife Refuge Invasive Species Inventory}

The U.S. Fish and Wildlife Service (USFWS) manages over 500 national wildlife refuges, encompassing nearly 93 million acres and representing every

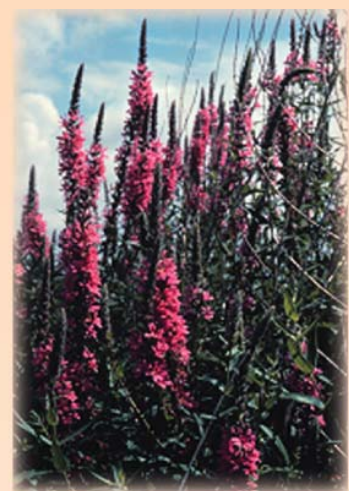

Fact Sheet 2004-3145 December 2004 
major ecosystem type in the U.S. All are experiencing non-native plant invasions that threaten the refuges' ability to fulfill their conservation mission. A cooperative study between the USGS and the USFWS entails developing and implementing a system for gathering invasive species information from all refuges and coordinating that data for managers, from local to national levels. With this synthesized information and the NBII Invasive Species Information Node, managers will be able to prioritize control efforts for non-native species already present on their refuges. In addition, they will be able to track other non-native species in their vicinities, so they will know which species to watch for and attempt to eradicate before they become well-established.

\section{NBII Invasive Species Information Node}

Working with NASA, the NBII, the Natural Resource Ecology Laboratory at Colorado State University, the Biota of North America Program (BONAP), several USGS Science Centers, and many others, FORT scientists and cooperators are developing a system for coordinating multiple types of data on both native and invasive nonnative species across the U.S. This information will be accessible over the World Wide Web in conjunction with analysis tools that will allow the user to, among other applications, summarize data for an area, query surrounding areas to determine what non-natives are encroaching, and even model where current non-native species are likely to be located. Currently, a demonstration site is being developed using vegetation data from Colorado.

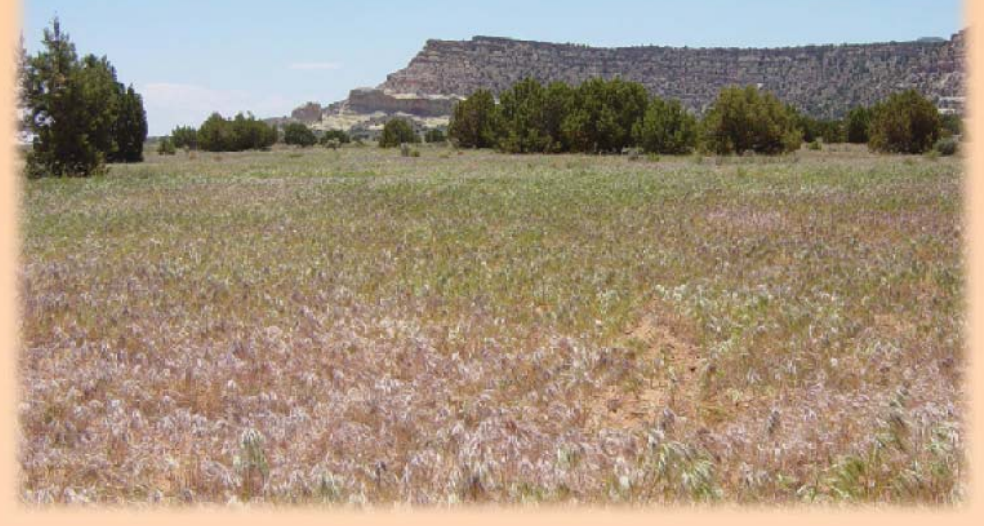

\section{Invasive Species Forecasting System}

Invasive plant species pose a major threat to the integrity of native plant communities, often threatening rare and endangered plant species as well. Predicting invasive plant behavior in vulnerable areas is key to controlling them. FORT and NASA scientists have initiated a three-year cooperative agreement with colleagues at Colorado State University to substantially improve predictive modeling capabilities for invasive plant species. In 2002, scientists began combining new rapid spatial-analysis techniques with highperformance computing capabilities for broad applications in "ecological forecasting" of the invasion process. Funded by the Computational Technologies Program at NASA's Goddard Space Flight Center, the study's test data sets will focus on, and immediately benefit, Rocky Mountain National Park, Grand StaircaseEscalante National Monument, and areas burned in the Cerro Grande Fire in the Santa Fe National Forest, New Mexico.

\section{Brown Treesnake}

The brown treesnake is responsible for the extirpation of nearly all native bird species and most bats and lizards on Guam. It also exacts between 1 and 4 million dollars per year in damages, including frequent power outages. Keeping this voracious snake from other noninfested islands, such as Hawaii and the Northern Marianas, is a top priority for the Department of the Interior's Office of Insular Affairs. In cooperation with other federal, state, and island agencies, FORT scientists working in Guam are making

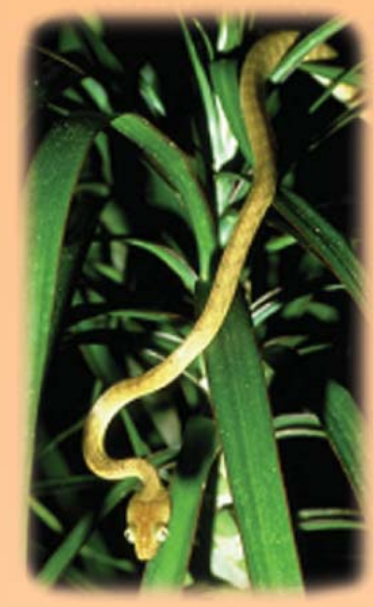
progress in toxicant research, trapping, population biology, venom research, and control strategies. In early 2002, they formed a Rapid Response Team to address potential brown treesnake sightings in the Pacific. Based in Guam, this interagency team includes trained brown treesnake "searchers." When local authorities request the team's services, the team quickly travels to the sighting location and uses all available tools, in cooperation with local counterparts, to capture the snake or limit an infestation.

\section{Staff}

Branch Chief: Tom Stohlgren, Ph.D. Ecologist: invasive species science, forest ecology, sampling techniques and design, resource inventory and monitoring, global change, grazing impacts, biodiversity.

Crosier, Catherine, Ph.D. Ecologist: non-native and invasive species, spatial modeling, landscape ecology.

Davern, Tracy, M.S. candidate. Student Trainee (Ecology): invasive species.

Kman, Teri, B.S. Wildlife Biologist: brown treesnake research and science communications.

Rodda, Gordon, Ph.D. Zoologist: brown treesnakes, introduced species and island habitats, population biology and behavior of reptiles and amphibians.

Stanford, James, M.S. Biologist: coordinator, brown treesnake Rapid Response Team.

VanGelder, Ellen, M.S. Wildlife Biologist: program manager, Brown Treesnake Project.

\section{Contact Information}

Tom Stohlgren, Branch Chief

U.S. Geological Survey, Fort Collins Science Center Natural Resource Ecology Laboratory, Colorado State University Fort Collins, Colorado 80523

Tel.970.491.1980 Fax 970.491.1965 tom_stohlgren@usgs.gov

\section{FORT Online}

Find information about FORT science, products, and resources at http://www.fort.usgs.gov

Learn more about the Invasive Species Science Branch at http://www.fort.usgs.gov/research/100/100.asp 